\title{
Explaining cross-cultural service interactions in tourism with Shenkar's Cultural Friction
}

\begin{abstract}
In this paper, we commence a new dialogue on cross-cultural research in tourism. Using Shenkar's (2001) metaphor of cultural friction as the analytical framework, we examine crosscultural service interactions between guests and service-providers in a luxury hotel. Cultural friction departs from, and extends, the notion of 'cultural distance', as it recognises asymmetry in social-economic conditions and considers the goals and the influence of control and power between the interacting parties. We use the Critical Incident Technique and Narrative Inquiry as the data collection technique and analytical approach respectively. The findings reveal that guests and service-providers use a number of strategies to exert power and gain control during their interactions, including subjective essentialism and stereotyping, to achieve their goals. The implications for tourism and hospitality management include providing cross-cultural sensitivity training to service-providers, ensuring a cultural-diverse employee composition, and to foster cross-cultural understanding amongst employees. We further suggest to develop strategies to facilitate effective cross-cultural service interactions based on evidence about cultural norms, expectations and behaviours from specific cultural groups. Further research is recommended to connect specific interactions between the interacting parties to examine whether the various strategies used leads to effective cross-cultural communication.
\end{abstract}

Keywords: Cultural friction, cross-cultural service interactions, subjective essentialism, stereotyping, cross-cultural research, hotel service-providers 


\section{Introduction}

Culture constitutes standards for decision-making (Goodenough, 1971) and is “...acquired knowledge that people use to interpret experience" to guide their behaviours (Spradley, 1979, p. 5). It is the "collective programming of the mind that distinguishes the members of one group or category of people from another" (Hofstede, 2001, p. 9). Thus, culture enables its members to interact with and communicate with those from the same, rather than another, group of people. However, with the advent of globalisation, migration, education and new technologies (Martin \& Nakayama, 2010; Reisinger, 2009), cross-cultural interactions are becoming more common with in a business context, and in particular in the service sector.

The service sector is the fastest growing economic sector - now accounting for two thirds of the global economic output (WTO, 2012), and today many service interactions involve serviceproviders of one culture interacting with customers from another culture (Sizoo, Plank, Iskat, \& Serrie, 2005). Differences in culture can shape and influence the outcomes of cross-cultural service interactions (Sizoo el at., 2005). As such, they add complexity to service interactions. Misunderstandings can, for example, eventuate in unhappy customers or frustrated serviceproviders (Cushner \& Brislin, 1996). Differences in culture can also create perceptions of mistrust and a 'us' versus 'them' perception in the two interacting parties (Hunter, 2001). Where service interactions between those of similar cultural backgrounds can suggest commonality and attractiveness (Hartel \& Fujimaoto, 2000; Yoo \& Sohn, 2003), interactions between those of dissimilar cultural backgrounds can suggest strangeness, anxiety, fear and conflict with, often negative, consequences (Neuliep \& Ryan, 1998). 
The tourism sector has experienced an increase in cross-cultural service interaction (Dimanche, 1994; Reisinger, 2009). Service interactions play a critical role in the overall tourism experience (Brunner-Sperdin \& Peters, 2009) as they are co-created by guests, or tourists, and service-providers (Prebensen \& Foss, 2011). In turn, the success of such interactions is dependent on the perceptions, expectations, rules of engagement and the communications of both parties involved (Reisinger, 2009; Tsang \& Ap, 2007). For example, a service-provider's appearance, behaviour, apparent lack of appreciation or difficulties in their communication, can leave guests with negative impressions of their service interactions (Walls, Okumus, Wang, \& Kwun, 2011, p. 181). The same outcome can occur for service-providers when guests are "authoritarian, arrogant, impolite, demanding and loud speaking” (Yeung \& Leung, 2007, p. 401).

Thus, cross-cultural service interactions in tourism influence the tourism experience and consequently the behaviour of the interacting parties (Hudson \& Ritchie, 2001). The nature of the interaction helps to determine the perceived purpose of the interaction and the expectations of both guests and host service-providers. As such, Dimanche (1994), advocates for a greater research focus on cultural differences in order to better understand tourism behaviour. Cultural differences may be accentuated in guest-host relationship in tourism because they are often embedded with asymmetrical social-economic status and concealed by inequality of power (Wearing, Stevenson, \& Young, 2010). Guests are often the 'haves' and the service providers the 'have nots' (Krippendorf, 1999).

This asymmetry is frequently displayed in cross-cultural service interactions in tourism. For example, some guests expect service-providers to be capable and professional and even 'friendly'- to welcome them as guests (Truong \& King, 2009). However, service-providers usually 
view guests as customers - entering into contractual economic relationships with them (Lashley, 2008). Thus, the goals of the interacting parties in this context are likely to differ between guests and service-providers. The unequal status is further complicated by interpersonal behavioural elements related to controlling the situation. As control is a basic human instinct exhibited in all social interactions (Bruce \& Thornton, 2004; Gecas, 1982, 1989), and a derivative for power (Pfeffer, 1981; Rucker, Galinsky, \& Dubois, 2011), it is very likley that both parties will seek to control the situation to achieve their goals.

Cultural differences, social-economic inequality and interpersonal behavioural elements of goals, power and control create a context for cross-cultural service interactions. Cole and Morgan (2010) suggest service interactions will continue to become increasingly important as tourism continues to grow and expand into new territories. Thus, there is a need for more complex and nuanced understandings of cross-cultural service interactions (Mattila, 1999b; Sharma, Tam, \& Kim, 2009; Sizoo et al., 2005; Winsted, 1997, 1999).

In order to more fully explore the complexities that lie within cross-cultural interactions, Doron (2005) and Maoz (2006) recommend moving towards exploring the interactive nature of the processes and to give consideration to interpersonal behavioural elements influencing crosscultural interactions. However, one of the greatest challenges in the traditional cross-cultural interaction paradigm is the lack in recognising the complexities of human relationships (Wearing et al., 2010). Therefore, one of the overall objectives of this paper is to address this deficiency by taking into consideration the asymmetrical social-economic condition of the interacting parties, and specifically exploring the interpersonal behavioural elements of goals, power and control in cross-cultural service interactions. 
In order to explore these concepts, we turn to Shenkar $(2001,2012)$ and Shenkar, Luo and Yeheskel's (2008) metaphor of 'cultural friction' (CF) as the theoretical framework. CF is described as 'the extent to which two or more entities from different countries culturally resist (i.e., think or act in opposition, shaped by implicit beliefs and tacit values) with one another' (Luo \& Shenkar, 2011, p. 2). We specifically explore CF's elements of goals, control and power in the context of cross-cultural service interactions and aim to explore how goals, control and power are mobilised in cross-cultural service interactions. Further, we aim to extract the meaning and the experience of cross-cultural service interactions within the context of international tourism using $\mathrm{CF}$ as an analytical framework and to explore the suitability of CF as an analytical framework for investigating cross-cultural service interactions within the context of international tourism. We achieve this through the examination of cases of cross-cultural service interactions in a luxury hotel, an environment where expectations of tailored service is likely to be high.

\section{Literature Review}

\section{Cross-cultural service interactions}

Cross-cultural service interactions are complex social encounters involving individual negotiations and subjective interpretations of the experiences that influence outcomes (Crouch, 1999). Outcomes of cross-cultural service interactions can be assessed along a continuum from those that are positive (which benefit the interacting parties) to those that are negative and disruptive (Smith, 1989). Negative interactions which result in anger and dissatisfaction can lead to service failures and can eventuate in complaints, negative word-of-mouth and loss of business 
(Lewis \& McCann, 2004). For these reasons, it is important to better understand cross-cultural service interactions as they determine both customer satisfaction (Winsted, 2000) and employee satisfaction (Sizoo et al., 2005).

Cross-cultural service interactions are increasingly common in tourism (Sharma et al., 2009), partly due to the bloom in tourism and hospitality (UNWTO, 2013) and the likelihood that service-providers and customers are from different nations (Reisinger, 2009). In tourism, very often the cross-cultural interactions are embedded with inequality, exploitation and unevenness (Wearing et al., 2010), as the interacting parties are seldom equal - socially or economically (Allen, 2004). The inequality is often complex and multidimensional involving perceptions of power and prestige (Lee, 2009). Typically, inequality is manifested in the asymmetrical socio-economic status but it is also concealed by inequality of power (Wearing et al., 2010), where guests are often the 'haves' and the service providers the 'have nots' (Krippendorf, 1999).

Additionally, in cross-cultural service interactions in tourism, the interacting parties' values, beliefs, expectations and knowledge are shaped by their respective cultural backgrounds, which impact the service interaction experiences (Mattila, 1999a). As culture determines actions and influences behaviours (Goodenough, 1971), scholars have suggested to focus on cultural differences because it is these differences that shape, influence and add complexity to service interactions (Dimanche, 1994; Hudson \& Ritchie, 2001). Particularly, Dimanche (1994), pointed out that focusing on cultural differences in cross-cultural research enables testing, learning and greater understanding of the cross-cultural phenomenon. 


\section{Revisiting cross-cultural paradigms}

To study such differences, a number of cross-cultural paradigms have been proposed. While no one metaphor can fully capture the meaning of culture or the effects of cultural differences (Smith, 2010), Cultural Distance (CD), or 'the difference in national cultures between two countries' (Kogut \& Singh, 1988, p. 414) has proven to be a popular tool to study and measure cultural differences. However, CD has not been without criticism. Shenkar $(2001 ; 2012)$ suggested that $\mathrm{CD}$ is founded on an illusion of symmetry, stability, linearity, causality and discordance, and the assumptions of corporate and spatial homogeneity and equivalence. Hence, scholars, including Luo and Shenkar (2011), Shenkar (2001; 2012), Shenkar et al. (2008), Zhang, Beatty and Walsh (2008), argue that CD is limited in its ability to shed light on cross-cultural interactions because of its tendency to focus on the dominant party (the 'haves') and failure to meaningfully consider the perspective of the less-dominant (the 'have nots') party, and to therefore realistically reflect the complexity of cross-cultural interactions.

To move beyond CD, Shenkar $(2001 ; 2012)$ and Shenkar et al. (2008) proposed the notion of $\mathrm{CF}$, with 'friction' metaphorically described as the rubbing of different cultures rather than to suggest conflict (Shenkar, 2001; 2012). CF was first applied in an organisational context to examine the challenges in cross-cultural business investment interactions involving differences between multinationals and developing nations (Shenkar et al., 2008). Its puprose was to assess the interaction between two different cultural parties and the scale and essence of the interface between their intertwined cultures. Further, Shenkar (2001; 2012) and Shenkar et al. (2008) suggested that the notion of 'friction' might be used as a new lens to extend knowledge of cross- 
cultural interactions beyond the current static horizon of $\mathrm{CD}$ and that it could be used to effectively describe and analyse cross-cultural interactions.

Thus, CF has the capacity to recognise the inequalities that exist in cross-cultural interactions, give 'voice' to the less-dominant party and pay attention to the asymmetrical imbalances in the social, economic, and cultural status between the interacting parties. Shenkar et al., (2008, p. 911) go so far as to suggest that CF offers a "paradigmatic shift in understanding organizational science behaviours critically with its embracement of subjective and social constructivist epistemological assumptions that gears towards a qualitative approach”. Shenkar et al. (2008) outline that in cross-cultural interactions in a business context CF is manifested via the interacting players (or actors), points of contact, cultural exchanges, asymmetry in the actors' goals, control and power, that shape and influence the outcomes of the cross-cultural interactions.

\section{Actors' goals, control and power in cross-cultural interactions}

The three key elements proposed by Shenkar et al. (2008) in CF was also suggested in previous studies to have an influence on cross-cultural interactions: goal-orientation (Lewis \& McCann, 2004; Price, Arnould, \& Tierney, 1995); power (Martin \& Nakayama, 2011); and control (Ji, Peng, \& Nisbett, 2000). Social interdependence theory, for example, suggests that interacting parties use power and control to shape the nature and the content of the interactions to their advantage with their behaviour impacting the outcomes of their interactions (Czepiel, 1990). The influence of the three elements in interaction can be seen in the following discussion. 


\section{Actors'goals}

In service interactions, the interacting parties are goal-oriented (Nikolich \& Sparks, 1995). When the goals of the interacting parties are similar, the actors are motivated towards interaction (Ellingsworth, 1988). In comparison, a divergence in goals can demotivate interaction (Amir, 1969) and result in conflicts that have negative consequences (Martin \& Nakayama, 2011). Within the context of tourism, Krippendorf (1999) suggests that service-providers and guests have contrasting goals; the guests' goals are for comfort and pleasure whereas the service-providers' goals are usually ‘economically' and task-oriented. We therefore explore goal incongruity between guests and service-providers to understand its influence on cross-cultural service interactions.

\section{Power}

Power is a general perception of authority/dominance; it is present in all human interactions resulting from inequalities in status among individuals and groups (Martin \& Nakayama, 2011). It is often manifested verbally through an affirmative loud tone, lower vocal pitch, bargaining, aversive complaining, ingratiation, or kindness (Afifi, 2007). Non-verbally, power is manifested through physical appearance, formal attire, facial expressions, body movements and spatial interpersonal space (Afifi, 2007). Elden (2001, p. 120) noted, for example, that: '...space is fundamental in any exercise of power', and suggested that people often use situations as opportunities to exercise power. However, power is relationally created. That is, people only have power if others choose to give it to them (Oetzel, 2009, p. 112), and without power, people might resort to negotiation or conflict (Martin \& Nakayama, 2011). Hence, power is thought to play an important role in shaping cross-cultural interactions (Martin \& Nakayama, 2011). 


\section{Control}

Perceptions of control are constructed from an individual's history of interactions in social and physical contexts (Skinner, 1995) suggeting they are important in cross-cultural service interactions (Bitner, 1990). Indeed, the need to control others is a central motive underlying human behaviour (Bruce \& Thornton, 2004; Gecas, 1982, 1989). Control can, for example, be gained through the possession of cultural knowledge about oneself and about the person(s) with whom one is interacting (Gasset, 2003). Control also indicates status or social dominance (Lustig \& Koester, 2006) and often manifested through 'assertive' verbal behaviours, such as giving a direct command or seeking collaboration (McElwain \& Volling, 2002).

While control is generally a pervasive personal feature (Skinner, 1995), studies have shown that different cultures exhibit different patterns of control (Ji et al., 2000). For example, a sense of being in control is less important for East Asians as it is for Americans (Ji et al., 2000). On the other hand, the need for control is found to be stronger for Westerners than for Asians (Sastry \& Ross, 1998). In service interactions, control is an important commodity desired by both customers and service-providers (Nikolich \& Sparks, 1995). For customers, the ability to control service interactions is a tool used to evaluate their service satisfaction (Winsted, 2000). Service-providers, on the other hand, have the ability to control the service interactions (Weaver, 2005) and have a general need to take control of the service interactions as part of their job performance (Whyte, 1977). They take control of service interactions when they initiate a conversation or smile - hoping to take control of the service interaction in its early stages to reduce potential conflict and stress in the service interaction (Nikolich \& Sparks, 1995). 
Considering the attributes and ways in which goals, power and control can emerge in crosscultural interactions, we suggest that there is a need to explore these elements in cross-cultural service interactions in the tourism sector and offer new sights into cross-cultural service interactions within this context. In adopting $\mathrm{CF}$ as a framework for analysis, we therefore include the voice of the service-providers. In this way, we extend the considerable body of research that has been garnered about the guest-host relationship in tourism (see, for example, Cohen, 1984; Smith, 1989; Thyne, Lawson, \& Todd, 2006), but overcome a gap that has emerged as a result of the tendency to take on the guests' perspective and overlooking the service-providers' perspective (Chan, 2006; Sharma et al., 2009; Yeung \& Leung, 2007). Thus, our study recognises the asymmetry in the social-economic conditions with the aim of obtaining a holistic understanding of cross-cultural service interactions in tourism.

We limited our study to the context of the luxury hotel sector where cross-cultural service interactions are prevalent and where they are critical for customers who desire high levels of service (Mattila, 1999a; Walls et al., 2011). In this context, the hotel is the point of contact and the

front-line service-providers and hotel guests are the 'players'. The cultural exchange is the content that is obtained from the respective parties', or actors', cultural systems.

\section{Methods and Data Collection}

As suggested by Shenkar et al. (2008), we used a qualitative approach to reveal deep insights into the cross-cultural interactions from both the guests' and service-providers' perspectives (van der Duim, Peters \& Wearing, 2005). We listen to both sides of the 'story' per se, 
using a subjective focus to reflect the continually changing, enacted and re-enacted social world in order to reveal deep insights into the complexity of cross-cultural service interactions (Shenkar et al., 2008). We used narrative inquiry, which is centred on the concept of 'experience' and allows participants to narrate and share their life experience in the form of stories (Polkinghorne, 1998) to obtain subjective interpretations from the insider's perspective (Connelly \& Clandinin, 2006). Narrative inquiry gains tacit knowledge about a phenomenon and can unfold, explore and discover emergent variables for new concepts. Narratives can be categorised into first order narratives, when individuals tells their stories; and, second order narratives when researchers recount or give account of stories of research participants to explain social phenomena (Carr, 1997).

In order to develop the narratives, we employed the critical incident technique, which involves participants recalling and retelling their most memorable or critical stories about specific negative cross-cultural service experiences (Douglas, McClelland, Davies, \& Sudbury, 2009). The critical incident technique is especially useful for exploring, describing and understanding new phenomenon or theory (Gremler, 2004). We explored for goals, power and control through first order narratives and for the discovery of any new emergent themes through second order narratives.

Our data were collected in Malaysia which has a population consisting of three distinct major ethnic groups: Malays, Chinese and Indians (Tourism Malaysia, 2010) making it a centre for cross-cultural interactions. Due to its geographical location, colonial history and population composition, tourism personnel in Malaysia interact with Europeans, Middle-Easterners, Americans, Australasians, Africans and Asians in a tourism context (Tourism Malaysia, 2010). We used a purposeful sample recruited using a snowballing technique (Bryman \& Bell, 2007) of 
a total 12 participants - six front-line service-providers who were working in a luxury hotel in Malaysia and six participants who had experience as guests in luxury hotels. This number of informants is well above qualitative scholars' recommendation regarding the minimum number of interviews to achieve saturation and variability (Guest, Bunce \& Johnson, 2006). To ensure our informants had sufficient experience in cross-cultural service interactions, the recruitment criteria included a minimum of three years of work experience in the luxury hotel sector for service providers and a minimum frequency of three international trips per year for guests. However, we acknowledge that while the informants are part of a dyad, our data is not truly dyadic in the sense that the data were not collected from actors from the same interaction (Watne \& Brennan, 2011).

A standard protocol was used to guide the face-to-face interviews, and probing was used when appropriate. The interview was divided into four key sections to enable the participants to focus their thinking on the different issues that related to the research: first, background to the research participant and of the identification memorable service interactions that the interview would be based around; second, the goals the participants had with regard to their service interactions; third, the nature and impact of culture in the service interactions - to elicit perceptions and feelings of power and control that emerged in the service interactions; and finally, the outcome of the service interactions for participants. Demographic information was also collected about the participants.

Once those approached had agreed to participate in the study, they were interviewed faceto-face in a location that was convenient for them and that enabled discussions to take place. The interviews, averaging 50 minutes in duration, were conducted in English, were recorded and transcribed, and later analysed around the key themes of the actors' goals, control and power. 
These formed the fundamental 'nodes' in NVivo. Increasingly, Nvivo is widely used in qualitative data analysis as it is a tool that facilitate qualitative inquiry through coding, sorting, linking, matching, modelling and visualising data (Bazeley \& Jackson, 2013). For this study, Nvivo was used to perform data storage, classification, linking and categorisation.

We used the nine evaluative criteria for the trustworthiness of the study and its findings, which social researchers have suggested to consider when undertaking interpretative research (Hede \& Thyne, 2010, Flint, Woodruff, \& Gardial, 2002; Lincoln \& Guba, 1985; Strauss \& Corbin, 1990). These are presented in Table 1.

$<$ Insert Table 1: "Trustworthiness of the study and findings (modelled on Hede \& Thyne, 2010)" about here>

\section{Findings and Discussion}

Table 2 provides the profiles of the research participants. As can be seen from Table 2, the research participants were diverse in terms of their cultural backgrounds, demographic profiles and had sufficient experience as expert informants.

<Insert Table 2: "Participant profiles" about here> 
We developed first-order narratives about each of the participants which we later analysed for commonalities and differences using the key themes from the elements of CF. Our analysis confirmed that Shenkar et al.'s (2008) three elements of actors' goals, control and power are relevant to cross-cultural service interactions.

\section{Actors'goals}

Our findings indicate that both guests' and service-providers' goals influence cross-cultural service interactions, which is consistent with earlier research within the context of business (Liu, 2011). Actors' goals were also found to influence whether the actors might assert power (Wilson \& Putnam, 1990). However, while Liu (2011) suggests that actors' goals are culturally-specific, this was not evident in our data. In our study, goals were found to fall into one of three categories: the task-oriented goals of the service-providers' (e.g. doing their job); the comfort-oriented goals of guests on business travel (e.g. being able to relax at the hotel); and the hedonistically-oriented goals of guest travelling for leisure (e.g. exploring a new place and culture). While asymmetry in goals is thought to demotivate the actors in cross-cultural interactions (Amir, 1969; Ellingsworth, 1988), this was also not evident in our data.

Nevertheless, we found that the differences in goals appear to influence expectations and behaviours in cross-cultural interactions, as suggested by Krippendorf (1999). For example, to attain their goals, some guests indicated that they expressed their dissatisfaction during the service interactions using aggression. In contrast, the service-providers' goals are often focussed on 
reducing such aggression and dissatisfaction. Chong, from Malaysia with a Chinese cultural background, offered a service-provider's perspective on this scenario stating:

...cross-cultural service interaction is not a choice as it is part of my job. It is important [in order] to do my job well.

Although the literature suggests that goal incongruity leads to cultural friction (Shenkar et al., 2008), our findings show that even though the goals of guests on business travel are similar to that of the front-line service-providers in that they are both task-oriented, this commonality did not necessarily promote interactions beyond those of the service transaction. In our study, Berlinda, on business travel from Indonesia, provides insights into how the purpose of her trip influences her pre-disposition to engage in with service-providers. She said:

...when I travel on a long trip into a foreign country, I just want to settle into my room as quickly as possible and get my things done...

Contrary to claims in the literature that goal incongruity discourages cross-cultural interactions (Shenkar et al., 2008), our data suggest that goal incongruity can encourage interactions. This is evidenced in Nata's narrative. Nata, who was on vacation from South Asia, and wanted 'to have fun' on her trip, wants to strike up conversations with service-providers who are job-oriented. She said that she likes to see how the 'locals' really live and said:

...When I travel, having fun and enjoyment is important. I like to explore the country, culture and interact with the people in their own environment... 
However, interactions within an international luxury hotel may not always be sufficiently cultural and satisfying in nature. Gunalan also from South Asia, who usually travels with his family, seeks cultural interactions that are less formal outside of the luxury hotel, such as bargaining for better prices in shopping, he said:

...for us, shopping and food are always the highlights. We always try to taste different types of food and explore as many shopping centres as possible...

\section{Control}

We found that both hotel guests and service-providers aimed to gain control (Burger \& Cooper, 1979) in their cross-cultural service interactions. This supports the view that control is a salient key instigator to service interactions (Bitner, 1990). McElwain and Volling (2002) suggested that control is most often manifested through assertive behaviours - this was apparent in our narratives. For example, when Johan, a Malaysian service-provider with a Malay cultural background, noted that:

...some Singaporeans hoping to get things their way by showing they are in control start with "I demand to speak to your manager" before they tell you the problem.

Feelings of a gained asymmetrical control are, however, merely perceptions (Rucker et al., 2011) and humans are often motivated to take advantage of situations to further help them gain control (Burger \& Cooper, 1979). In this example, the Singaporean guest refuses to pay service tax and creates 'a scene' citing that her own country services are not taxed. As Singapore is an 
economically predominant influence in the Asia-Pacific region, the guest seems to exercise hegemonic control as a result of her country of origin.

Amelia, a service-provider from Malaysia with a Chinese cultural background, said that guests from South Asia often request not to be served by Malaysians of South Asian descent, because of the differences in social class and because they are more comfortable being served by Malaysian Chinese or Malay. Here, control also acts as an indicator of social status between the 'haves', those with access to power, privilege and resources not having to deal with the 'have nots' (Lustig \& Koester, 2006). In addition, control can be obtained through cultural knowledge (Gasset, 2003). Berlinda, who travels for business frequently, found very quickly that her efforts to learn some essential foreign phrases can help prevent potential friction in service interactions:

...I always learn a few simple words like "good morning" and "thank you" in the local language that always impress them and get them to be more helpful.

\section{Power}

When power is exerted by tourists, negative consequences are often produced (Cheong \& Miller, 2000). In our study, the hotel guests' power becomes apparent in cross-cultural service interactions when they try and take advantage of the public space to gain better service (Afifi, 2007; Elden, 2001). For example, Narul, a service-provider from Indonesia, spoke of how some Asian guests behave at check-in to assert their power and status; a behaviour that perhaps is reflected in the 'haves' need to assert power over the 'have nots'. She said: 
...some of them will raise their voice...to grab attention from the surrounding guests, creating a scene in the hope of receiving a quicker check-in.

Hui-Yee, a Malaysian Chinese service-provider, offered another perspective which reflects a behaviour related to the 'haves' need to assert power over the 'have nots'. Hui-Yee said:

...the new rich [referring to socially mobile Chinese guests] - if they find a hair in their food, they will shout, so that the other people can hear. While they don't want any compensation, they certainly want to attract attention to show that they are different.

Gunalan, a guest from South Asia, sees attire as a means of gaining power. He explained:

...it's not common to dress in a T-shirt and jeans [for professionals] in our culture, it is seen as less formal.... if you want to get better attention in service, you need to dress formally.

In analysing the narratives, we discovered emergent concepts from the second-order narratives. We consider them as controlling techniques for cross-cultural service interactions and grouped them under the name "controlling techniques".

\section{Controlling techniques}

Based on the second-order narratives, two concepts were identified that assist to understand cross-cultural service interactions: subjective essentialism (Rothbart \& Taylor, 1992) and 
stereotyping (Yzerbyt \& Rocher, 2002). We refer to these as 'controlling techniques' and propose them as an additional element for consideration in $\mathrm{CF}$ in relation to service interactions.

Our analysis indicates that both the guests and front-line service-providers used controlling techniques related to subjective essentialism and stereotyping to help them make sense of, and manage, their cross-cultural interactions. In particular, the service-providers use past experiences and cultural knowledge shared by their colleagues to develop these controlling techniques. They use the controlling techniques to gain control and assert power in order to manage the situation and elevate their position to their advantage from being the 'have nots' and the 'powerless'.

\section{Subjective essentialism}

We found that both the service-providers and the guests in our study categorised and essentialised their counterparts into social categories using some form of a priori knowledge (Nikolich \& Sparks, 1995; Yzerbyt \& Rocher, 2002). This process is desribed as subjective essentialism (Rothbart \& Taylor, 1992). People are known to essentialise others based on, for example, naïve beliefs (Demoulin, Leyens, \& Yzerbyt, 2006; Yzerbyt \& Rocher, 2002) or their gender, race, ethnic categories or subcultural groupings (Prentice \& Miller, 2007). Subjective essentialism is referred to as 'people's tendency to act as if things (objects) have essences or underlying natures that make them the things they are' (Medin, 1989, page 1476).

While our findings are consistent with earlier findings about service-providers' unfavourable perception of guests (Yeung \& Leung, 2007), our data highlights that, people often (mis)attribute essences (which they think are by nature) to social groups. That is, they tend to 
assume that group members share with one another something deep inside that differentiates their group from other groups in their social environment (Demoulin et al., 2006). This misattribution was particularly evident in John's narrative. John, from New Zealander, said he did not expect front-line service-providers in Malaysia to speak English well. He categorised them using preconceived perceptions relating to his own expectations of their culture. However, just as Rothbart and Taylor (1992) cautioned that not everyone's naïve beliefs and known knowledge about different social groups are accurate, John's a priori categorisation was incorrect. John recalled, in fact, how 'easy it was' for him to communicate with the service-providers.

...I was prepared to use sign language if necessary...I didn't expect them to be able to understand and speak English. They spoke good English. I am impressed.

The reverse situation, whereby a service-provider has inaccurate expectations of the guests and as such misattribute them can also occur. For example, Peng Yin, a guest, spoke about how service-providers in China often had unrealistic expectations of him when they essentialise him:

...just because I am a Malaysian Chinese, the hotel employees in China expect me to speak Mandarin and know everything about the Chinese custom. I am sorry. Not all Chinese in Malaysia speak Mandarin.

However, subjective essentialism had potential to assist our research participants to gain control and assert power in managing their cross-cultural interactions. This assertion came to the fore for Chong, a service-provider, commented that, in his view, Australians were not experienced travellers. This opinion influenced his expectations of them, as well as his expectations of Australians' knowledge of his customs and culture. He said: 
...we don't expect them [Australians] to know about our Malaysian customs and culture.

Yzerbyt, Corneille and Estrada (2001) suggested that the subjective essentialism of groups leads to generalisation and formation of stereotyping eventually.

\section{Stereotyping}

While subjective essentialism explains attributing essences to social groups based on some a priori knowledge, stereotyping is about explaining the attribution to particular social groups (Hilton \& von Hippel, 1996). Stereotypes are beliefs about the characteristics, attributes, and behaviours of members of certain groups (Hilton \& von Hippel, 1996). Accordingly, there are different representational models that shows how stereotypes are represented in the minds of individuals, one of which is through 'schemas' (Hilton \& von Hippel, 1996). Stereotypes based on schemas suggest that people use generalized knowledge and highly abstract beliefs to categorise groups and their members (Fiske \& Taylor, 1991). Stereotypes can be positive or negative (Moufakkir, 2011, p. 79). Although stereotypes are not necessary negative in nature, they are likely associated with negative connotations (Hilton \& von Hippel, 1996). Both tourists and hosts are prone to stereotype each other most commonly through nationality (Brewer, 1984; Moufakkir, 2011).

Indeed, some of the service-providers we interviewed indicated that they had the tendency to stereotype guests based on their cultural backgrounds. For example, Johan, a service-provider from a Malay background, believed that South Asian guests were typically loud and demanding: 
...they always demand to have the same as their fellow group members. They insist on having the same type of room as the others.

Stereotyping helps one to exert control and maintain power (Fiske, 1993). In this study, it was found that stereotypes are shared with colleagues and viewed as critical information that can be used to effectively control cross-cultural interactions and the powerless service employee to maintain power. Narul, learned very quickly from her service-provider colleagues about South East Asia guests travelled in groups, she said:

...my colleagues told me that guests from South East Asian usually travel in large numbers and they love to shop ending up having excess baggage...they also have poor time management that often results in late check-ins and check-out.

The implications of stereotyping have been argued for favourably because stereotyping provides subjective meaning, aiding perceivers to deal with a situation with pre-existing information (Yzerbyt \& Rocher, 2002). Also, stereotyping provides an explanation for certain group behaviour and rationalisation for why things are the way they are (Crawford, Sherman, \& Hamilton, 2002). McGarty, Yzerbyt and Spears (2002) suggested that stereotypes were aids to explanation, energy-saving devices, and shared group beliefs. In hospitality, stereotyping plays an important role in aiding service delivery process and assisting guests in informing judgement on the service delivery (Nikolich \& Sparks, 1995).

A summary of the first and second order narratives according to key themes is summarised in Table 3.

$<$ Insert Table 3: "Narrative summary table" about here> 


\section{Conclusion}

This study sought to better understand actors' goals, control and power are mobilised in cross-cultural service interactions using CF as our conceptual framework. Our findings indicate that the elements of actors' goals, control and power are key aspects in shaping and influencing cross-cultural interactions. Guests' and the service-providers' goals of the cross-cultural interaction are sometimes different. The actors' goals within this context seem to be situationallydependent rather than culturally-dependent. The guests' goals seem to be first related to the purpose of their trip and then to their culture, whereas the service-providers' goals are often taskoriented. In some cases, particularly in the case of business travel, both parties aim to minimise their interactions with the other party as much as possible.

Further, guests often exhibit various aggressive (shouting, demanding) or non-aggressive (dress code) behaviours to assert power over the 'have nots' in order to gain control over the situation. Additionally, both the service-providers and the guests use embedded controlling techniques (subjective essentialism and stereotyping) to help them cope and gain control and assert power over cross-cultural service interactions.

The likelihood of a guest asserting power and gaining control seems, however, to be largely culturally dependent. The front-line service-providers referred to people of particular cultural cohorts when they recounted their experiences when power and control were exerted and gain by guests. In turn, it was demonstrated that the front-line service-providers developed controlling techniques relating to different cultures. It seems that the front-line service-providers are equipped 
with expertise to manage a guest's behaviour. The accumulation of their expertise and cultural knowledge assists them to become the 'haves' rather than being the 'have nots'.

Our findings do not appear to support the "similarity hypothesis"- that more positive interactions eventuate between actors from similar cultures (Adler \& Graham, 1989), nor the suggestion that the closer the cultures appear to be, the greater likelihood of positive interactions (Volet \& Ang, 1998). Rather, our findings support the view that when the cultural differences between the guest and the service-provider are less apparent, power is more likely to be asserted and the need to gain control over the situation seems to be more dominate the interactions (Weiermair \& Fuchs, 2000). For example, issues surrounding power and control were evident in the interactions between Chinese and Malaysian Chinese, South Asians and Malaysian South Asians as well as Singaporeans and Malaysians. This finding suggests that when cultures are 'closer' the actors may become insecure or competitive which motivates them to exert power and gain control.

We conclude that $\mathrm{CF}$ is a suitable analytical framework to explore cross-cultural interactions within international tourism service particularly when the guests and service-providers have asymmetry in social and economic status. Our study has revealed how asymmetry in goals, together with control and power, shape the interactions. The controlling techniques we found help explain how guests and service-providers deal with cross-cultural service interactions.

\section{Managerial Implications}


Our findings highlight that while guests are motivated to exert power and gain control; their behaviour has the potential to induce emotional stress for the service-providers. As such, there are several important implications for tourism and hospitality management. Management can assist service-providers to ameliorate these negative effects by providing cross-cultural sensitivity training to promote cultural understanding and aid cross-cultural interaction. In past, such trainings were normally provided to managers but seldom to front-line service-providers (Shapero, 2011). Management can also ensure that there is cultural diversity within the composition of their employees and encourage sharing of culture and foster effective interaction under cultural differences. As guests' service expectation is largely influence by different in cultures, management can help develop general strategies based on evidence about cultural norms, expectations and behaviours for specific cultural groups, such as European, Asian and MiddleEastern. These strategies can equip service-providers from various cultures to interact with guests from various cultures and enhance their cross-cultural experience. More importantly, management needs to optimise the interpersonal interaction in service encounter as they are often the 'momentof-truth' (Brunner-Sperdin, Peters, \& Strobl, 2012) and emphasise to service-providers the importance of this moment to customers' service satisfaction.

\section{Limitations and Future Research}

This study was conducted with representative members of the service-provider/guest dyad. Further research with, pairing of the dyad representatives will extend this research and provide further insights into the complexity of cross-cultural service interactions in tourism. Future research can now build a dyadic inquiry on the elements of goals, power, control and controlling techniques. Such research might focus on using an 'observation-based' paired dyadic approach, 
such as through videoing to observe the interactions in situ. This may provide further insights into how CF manifests itself in the actors in cross-cultural service interactions in tourism.

Using the critical incident technique was an effective means for developing the narratives. However, because we undertook this research in an international luxury hotel, our narratives only relate to this particular research context. While this is a limitation of the study's findings, it provides opportunities for further research in other contexts where cross-cultural service interactions occur. For example, extending this research to different accommodation options, such as backpacker hostels, or other market offerings in tourism may elicit new or different findings. While the a total 12 participants of which six were guests and six service-providers were interviewed as part of this study, undertaking a larger number of interviews will provide more examples and wider coverage surrounding the topic of goals, control, and power.

To date, most studies on cross-cultural service interactions in tourism have adopted a Western-centric perspective [see, for example, Lewis and McCann (2004), Weiermair and Fuchs (2000)]. Little attention has been given to the 'guests' from a non-Western perspective (Truong \& King, 2009). While this study attempts to address this deficiency in the literature, further work is needed to gain the views of the various key players or cross-cultural service interactions, who are not directly involved in cross-cultural services interactions, such as family members and travel partners, tour guides, or managers of the service-providers. Such an approach would take this research into a new domain beyond the dyad, when, for example, actor network theory may prove to be a useful framework for analysis. 


\section{References}

Adler, N. J., \& Graham, J. L. (1989). Cross-cultural interaction: the international comparison fallacy. Journal of International Business Studies, 20(3), 515-537.

Afifi, W. A. (2007). Nonverbal communication. In B.B. Whaley, \& W. Samter (Eds.), Explaining communication contemporary theories and exemplars (pp. 39-62). New Jersey: Lawrence Erlbaum Associates, Publishers.

Allen, B. J. (2004). Difference matters: Communicating social identity. Long Grove: Waveland Press, Inc.

Amir, Y. (1969). Contact hypothesis in ethic relations. Psychological Bulletin, 71(5), 319-342.

Bazeley, P., \& Jackson, K. (2013). Qualitative Data Analysis with NVivo. London: SAGE Publications.

Bitner, M. J. (1990). Evaluating service encounters: The effects of physical surroundinggs and employee responses. Journal of Marketing, 54(April), 69-82.

Brewer, J. D. (1984). Tourism and ethnic stereotypes. Variations in a Mexican town. Annals of Tourism Research, 11(3), 487-501.

Bruce, M. A., \& Thornton, M. C. (2004). It's my world? Exploring black and white perceptions of personal control. The Sociological Quarterly, 45(3), 597-612.

Brunner-Sperdin, A., \& Peters, M. (2009). What influences guests' emotions? The case of highquality hotels. International Journal of Tourism Research, 11(2), 171-183

Brunner-Sperdin, A., Peters, M., \& Strobl, A. (2012). It is all about the emotional state: Managing tourists' experiences. International Journal of Hospitality Management, 31(1), 23-30.

Bryman, A., \& Bell, E. (2007). Business research methods. Oxford: Oxford University Press.

Burger, J., \& Cooper, H. (1979). The desirability of control. Motivation and Emotion, 3(4), 381393.

Carr, D. (1997). Narrative and the real world: An arguement for continuity. In L.P. Hinchman, \& S.K. Hinchman (Eds.), Memory, identity, community: The idea of narrative in the human sciences (pp. 7-25). New York: State University of New York.

Chan, Y. W. (2006). Coming of age of Chinese tourists, the emergence of non-western tourism and host-guest interactions in Vietnam's border tourism. Tourist Studies, 6(3), 187-213. 
Cheong, S. M., \& Miller, M. L. (2000). Power and tourism: A Foucauldian observation. Annals of Tourism Research, 27(2), 371-390.

Cohen, E. (1984). The sociology of tourism: Approaches, issues, and findings. Annual Review of Sociology, 10(1), 373-392.

Cole, S., \& Morgan, N. (Eds.). (2010). Introduction:Tourism and inequalities. Wallingford: CABI International.

Connelly, M., \& Clandinin, J. (2006). Narrative Inquiry. In J.L. Green, G.A. Camilli, \& P. B. Elmore (Eds.), Handbook of complementary methods in education research (Third ed.), (pp. 477-489). Mahwah, NJ: Lawrence Erlbaum Associates.

Crawford, M. T., Sherman, S. J., \& Hamilton, D. L. (2002). Perceived entitativity, stereotype formation, and the interchangeability of group members. Journal of Personality and Social Psychology, 83(5), 1076-1094.

Crouch, D. (1999). Introduction: Encounters in leisure/tourism. In Crouch, D. (Ed.), Leisure/Tourism geographies: Practices and geographical knowledge (pp. 1-16). London: Routledge.

Cushner, K., \& Brislin, R. (1996). Intercultural Interactions: A Practical guide. Thousand Oaks: Sage Publications.

Czepiel, J. A. (1990). Service encounters and service relationships: implications for research. Journal of Business Research, 20(1), 13-21.

Demoulin, S., Leyens, J.-P., \& Yzerbyt, V. (2006). Lay Theories of Essentialism. Group Processes \& Intergroup Relations, 9(1), 25-42.

Dimanche, F. (1994). Cross-Cultural Tourism Marketing Research. Journal of International Consumer Marketing, 6(3-4), 123-160.

Doron, A. (2005). Encountering the 'Other': Pilgrims, tourists and boatmen in the city of Varanasi. The Australian Journal of Anthropology, 16(2), 157-178.

Douglas, J., McClelland, R., Davies, J., \& Sudbury, L. (2009). Using critical incident technique (CIT) to capture the voice of the student. The TQM Journal, 21(4), 305-318.

Elden, S. (2001). Mapping the present: heidegger, Foucalt and the Project of spatial history. New York: Continuum.

Ellingsworth, E. (1988). A Theory of Adaptation in Intercultural Dyads. In Y. Y Kim, \& W.B.

Gudykunst (Eds.), Theories in intercultural communication (pp. 259-279). Newbury Park: Sage Publications, Inc. 
Fiske, S. T., \& Taylor, S. E. (1991). Social cognition (2nd ed.). New York: Mcgraw-Hill Book Company.

Fiske, S. T. (1993). Controlling other people: The impact of power on stereotyping. American Psychologist, 48(6), 621-628.

Flint, D., Woodruff, R., \& Gardial, S. F. (2002). Exploring the phenomenon of customers' desired value change in a business-to-business context. Journal of Marketing, 66(4), 102117.

Gasset, J. O. (2003). Communicating Effectively with Strangers. In Y. Y Kim, \& W.B. Gudykunst (Eds.), Communicating with strangers: An approach to intercultural communication (pp. 269-294). New York: McGraw-Hill.

Gecas, V. (1982). The self-concept. Annual Review of Sociology, 8(1), 1-33.

Gecas, V. (1989). The social psychology of self-efficacy. Annual Review of Sociology, 15(1), 291-316.

Goodenough, W. (1971). Culture, language, and society. MA: Addison-Wesley.

Gremler, D. (2004). The critical incident technique in service research. Journal of Service Research, 7(1), 65-89.

Guest, G., Bunce, A., \& Johnson, L. (2006). How many interviews are enough? an experiment with data saturation and variability. Field Methods, 18(1), 59-82.

Hartel, C., \& Fujimaoto, Y. (2000). Diversity is not a problem to be managed by organizations but openness to perceived dissimilarity is. Journal of Australian and New Zealand Academy of Management, 6(1), 14-27.

Hede, A.-M., \& Thyne, M. (2010). A journey to the authentic: Museum visitors and their negotiation of the inauthentic. Journal of Marketing Management, 26(7/8), 686-705.

Hilton, J. L., \& von Hippel, W. (1996). Stereotypes. Annual Review of Psychology, 47(1), 237271.

Hofstede, G. (2001). Cultures consequences (2nd ed.). Thousand Oaks, CA: Sage.

Hudson, S., \& Ritchie, J. R. B. (2001). Cross- cultural tourist behavior: An analysis of tourist attitudes towards the environment. Journal of Travel \& Tourism Marketing, 10(2-3), 122.

Hunter, W. C. (2001). Trust between culture: The tourist. Current Issues in Tourism, 4(1), 42-67. 
Ji, L.-J., Peng, K., \& Nisbett, R. E. (2000). Culture, control, and perception of relationships in the environment. Journal of Personality and Social Psychology, 78(5), 943-955.

Kogut, B., \& Singh, H. (1988). The effect of national culture on the choice of entry mode. Journal of International Business Studies, 19(3), 411-432.

Krippendorf, J. (1999). The Holiday Makers Understanding the Impact of Leisure and Travel. Oxford: Butterworth-Heinemann.

Lashley, C. (2008). Marketing hospitality and tourism experiences. In O. Haemoon, \& A. Pizam (Eds.), Handbook of hospitality marketing management (pp. 3-32). Oxford: ButterworthHeinemann.

Lee, S. (2009). Income inequality in tourism services-dependent counties. Current Issues in Tourism, 12(1), 33-45.

Lewis, B., \& McCann, P. (2004). Service failure and recovery: evidence from the hotel industry. International Journal of Contemporary Hospitality Management, 16(1), 6-17.

Lincoln, Y., \& Guba, E. (1985). Naturalistic Inquiries. Beverly Hills: Sage Publications.

Liu, M. (2011). A phasic analysis of strategy sequences and their mediating effects on interaction goals and negotiation outcomes. Communication Research, 38(2), 248-277.

Luo, Y., \& Shenkar, O. (2011). Toward a perspective of cultural friction in international business. Journal of International Management, 17(1), 1-14.

Lustig, M., \& Koester, J. (2006). Intercultural competence, interpersonal communication across cultures. Boston: Pearson Education, Inc.

Maoz, D. (2006). The mutual gaze. Annals of Tourism Research, 33(1), 221-239.

Martin, J., \& Nakayama, T. (2010). Intercultural Communication in Contexts (5th ed.). New York: McGraw-Hill.

Martin, J., \& Nakayama, T. (2011). Experiencing intercultural communication: An introduction. New York: McGraw-Hill.

Mattila, A. (1999a). The role of culture and purchase motivation in service encounter evaluations. Journal of Service Marketing 13(4/5), 376-389.

Mattila, A. (1999b). The role of culture in the service evaluation process. Journal of Service Research 1(3), 250-261.

Medin, D. L. (1989). Concepts and conceptual structure. American Psychologist, 44(12). 
McElwain, N., \& Volling, B. (2002). Relating individual control, social understanding, and gender to child-friend interaction: a relationships perspective. Social Development, 11(3), 362-385.

McGarty, C., Yzerbyt, V., \& Spears, R. (2002). Social, cultural and cognitive factors in stereotype formation. In C. McGarty, V.Y. Yzerbyt, \& R. Spears (Eds.), Stereotypes as explanations the formation of meaningful beliefs about social groups (pp. 1-16). Port Chester, NY: Cambridge University Press.

Moufakkir, O. (2011). The Role of Cultural Distance in Mediating the Host Gaze. Tourist Studies, 11(1), 73-89.

Neuliep, J. W., \& Ryan, D. J. (1998). The influence of intercultural communication apprehension and socio-communicative orientation on uncertainty reduction during initial crosscultural interaction. Communication Quarterly, 46(1), 88-99.

Nikolich, M. A., \& Sparks, B. A. (1995). The hospitality service encounter: The role of communication. Journal of Hospitality \& Tourism Research, 19(2), 43-56

Oetzel, J. G. (2009). Intercultural communication - A layered approach. New Jersey: Pearson Education, Inc.

Pfeffer, J. (1981). Power in organizations. Marshfield: Pitman.

Polkinghorne, D. (1998). Narrative knowing and the human sciences. New York: State University of New York Press.

Prebensen, N. K., \& Foss, L. (2011). Coping and co-creating in tourist experiences. International Journal of Tourism Research, 13(1), 54-67.

Prentice, D. A., \& Miller, D. T. (2007). Psychological essentialism of human categories. Current Directions in Psychological Science, 16(4), 202-206.

Price, L. L., Arnould, E. J., \& Tierney, P. (1995). Going to extremes: Managing service encounters and assessing provider performance. Journal of Marketing, 59(April), 83-97.

Reisinger, Y. (2009). International tourism cultures and behaviour. Burlington: ButterworthHeinemann.

Rothbart, M., \& Taylor, M. (1992). Category labels and social reality: do we view social categories as natural kinds? In G.R. Semin, \& K. Fiedler (Eds.), Language, Interaction and social cognition (pp.11-36). London: Sage Publication, Ltd.

Rucker, D. D., Galinsky, A. D., \& Dubois, D. (2011). Power and consumer behavior: How power shapes who and what consumers value. Journal of Consumer Psychology, 22(3), 352-368. 
Sastry, J., \& Ross, C. E. (1998). Asian ethnicity and the sense of personal control. Social Psychology Quarterly, 61(2), 101-120.

Shapero, M. (2011). Cross-cultural training for hospitality and tourism: Improving service encounters through industry targeted critical incidents. 1-9. Retrieved from Comparative Cultures Collegium website: http://proxy.eckerd.edu/academics/internationalbusiness/files/shapero_summer_06.pdf

Sharma, P., Tam, J., \& Kim, N. (2009). Demystifying intercultural service encounters toward a comprehensive conceptual framework. Journal of Service Research, 12(2), 227-242.

Shenkar, O. (2001). Cultural distance revisited: towards a more rigorous conceptualization and measurement of cultural differences. Journal of International Business Studies, 32(3), 519-535.

Shenkar, O., Luo, Y., \& Yeheskel, O. (2008). From "distance" to "friction": Substituting metaphors and redirecting intercultural research. Academy of Management Review, 33(4), 905-923.

Shenkar, O. (2012). Beyond cultural distance: Switching to a friction lens in the study of cultural differences. J Int Bus Stud, 43(1), 12-17.

Sizoo, S., Plank, R., Iskat, W., \& Serrie, H. (2005). The effect of intercultural sensitivity on employee performance in cross-cultural service encounters. Journal of Services Marketing, 19(4), 245-255.

Skinner, E. A. (1995). Perceived control, motivation, \& coping. Thousand Oaks: Sage Publications Inc.

Smith, B. (2010). Software, distance, friction, and more: a review of lessons and losses in the debate for a better metaphor on culture. Advances in International Management, 23(1), 213-229.

Smith, V. (1989). Introduction: Hosts and Guests: The Anthropology of Tourism. In V. Smith (Ed.), Hosts and Guests: The Anthropology of Tourism (pp.1-21). Philadelphia: University of Pennsylvania Press.

Spradley, J. P. (1979). The ethnographic interview. New York: Holt, Rinehart and Winston.

Strauss, A. L., \& Corbin, J. M. (1990). Basics of qualitative research: grounded theory procedures and techniques. Thousand Oaks: Sage Publications.

Thyne, M., Lawson, R., \& Todd, S. (2006). The use of conjoint analysis to assess the impact of the cross-cultural exchange between hosts and guests. Tourism Management, 27(2), 201213. 
Tourism Malaysia. (2010). About Malaysia, truly Asia. Retrieved from http://www.tourism.gov.my/en/about/default.asp/

Truong, T.-H., \& King, B. (2009). An evaluation of satisfaction levels among Chinese tourists in Vietnam. International Journal of Tourism Research, 11(6), 521-535.

Tsang, N. K.-F., \& Ap, J. (2007). Tourists' perceptions of relational quality service attributes: A cross-cultural study. Journal of Travel Research, 45(3), 355-363.

UNWTO. (2013). International tourism demand exceeds expectations in the first half of 2013. Retrieved 3/10/2013, from UNWTO Barometer http://media.unwto.org/en/pressrelease/2013-08-25/international-tourism-demand-exceeds-expectations-first-half-2013

van der Duim, R., Peters, K., \& Wearing, S. (2005). Planning host and guest interactions: Moving beyond the empty meeting ground in African encounters. Current Issues in Tourism, 8(4), 286-305.

Volet, S. E., \& Ang, G. (1998). Culturally mixed groups on international campuses: an opportunity for inter-cultural learning. Higher Education Research \& Development, $17(1), 5-23$.

Walls, A., Okumus, F., Wang, Y., \& Kwun, D. J.-W. (2011). Understanding the consumer experience: An exploratory study of luxury hotels. Journal of Hospitality Marketing \& Management, 20(2), 166-197.

Watne, T., \& Brennan, L. (2011). Behavioral Change Starts in the Family: The Role of Family Communication and Implications for Social Marketing. Journal of Nonprofit \& Public Sector Marketing, 23(4), 367-386. doi: 10.1080/10495142.2011.623526

Wearing, S., Stevenson, D., \& Young, T. (2010). Tourist cultures, identity, place and the traveller. London: Sage Publications Ltd.

Weaver, A. (2005). Interactive service work and performative metaphors: The case of the cruise industry. Tourist Studies, 5(1), 5-27.

Weiermair, K., \& Fuchs, M. (2000). The impact of cultural distance on perceived service quality gaps: the case of Alpine tourism. Journal of Quality Assurance in Hospitality \& Tourism, I(2), 59-76.

Whyte, W. F. (1977). Human Relations in the Restaurant Industry. New York: Arno Press.

Wilson, S. R., \& Putnam, L. L. (1990). Interaction goals in negotiation. In J.A. Anderson (Ed.), Communication yearbook 13 (pp. 374-406). Newbury Park: Sage.

Winsted, K. F. (1997). The service experience in two cultures: A behavioral perspective. Journal of Retailing, 73(3), 337-360. 
Winsted, K. F. (1999). Evaluating service encounters: A cross-cultural and cross-industry exploration. Journal of Marketing Theory \& Practice, 7(2), 106.

Winsted, K. F. (2000). Service behaviors that lead to satisfied customers. European Journal of Marketing, 34(3/4), 399 - 417.

WTO (World Trade Organization) (2012). Services: rules for growth and investmentUnderstanding the WTO: The agreements. Retrieved from World Trade Organization Web site: http://www.wto.org/english/thewto_e/whatis_e/tif_e/agrm6_e.htm

Yeung, S., \& Leung, C. (2007). Perception and attitude of Hong Kong hotel guest-contact employees towards tourists from Mainland China. International Journal of Tourism Research, 9(6), 395-407.

Yoo, J., \& Sohn, D. (2003). The structure and meanings of intercultural interactions of international tourists. Journal of Travel and Tourism Marketing 14(1), 55-68.

Yzerbyt, V., Corneille, O., \& Estrada, C. (2001). The interplay of subjective essentialism and entitativity in the formation of stereotypes. Personality and Social Psychology Review, $5(2), 141-155$.

Yzerbyt, V., \& Rocher, S. (2002). Subjective essentialism and the emergence of stereotypes. In C. McGarty, V.Y. Yzerbyt, \& R. Spears (Eds.), Stereotypes as explanations the formation of meaningful beliefs about social groups (pp. 38-66). Port Chester, NY: Cambridge University Press.

Zhang, J., Beatty, S., \& Walsh, G. (2008). Review and future directions of cross-cultural consumer services research. Journal of Business Research, 61(3), 211-224. 
Table 1: Trustworthiness of the study and findings (modelled on Hede \& Thyne, 2010)

\begin{tabular}{|c|c|}
\hline Trustworthiness Criteria & Method of addressing in this study and findings \\
\hline Credibility & \\
\hline $\begin{array}{l}\text { Extent to which the data source and results appear to } \\
\text { be acceptable representations of the study. }\end{array}$ & $\begin{array}{l}\text { The three researchers were involved in the research } \\
\text { conceptualisation, design, data collection and interpretation. } \\
\text { Collection and analysis of data was undertaken over a period of } \\
19 \text { months on incremental basis. Equal number of six hotel } \\
\text { service providers and six guests from diverse ethnic } \\
\text { backgrounds were recruited. Informal elite interviews were held } \\
\text { with hotel manager before and after the interviews for } \\
\text { solicitation and verification of information and provision of } \\
\text { feedback. }\end{array}$ \\
\hline Transferability & \\
\hline $\begin{array}{l}\text { Extent to which the findings from one study in one } \\
\text { context will apply to other contexts. }\end{array}$ & $\begin{array}{l}\text { Research design involving critical incident technique and semi- } \\
\text { structured in-depth interview to gather narratives has been } \\
\text { employed in numerous luxury hotel service studies. }\end{array}$ \\
\hline Dependability & \\
\hline $\begin{array}{l}\text { Extent to which the findings are unique to time and } \\
\text { place; the stability or consistency of explanations. }\end{array}$ & $\begin{array}{l}\text { Research participants were briefed by the researcher on the } \\
\text { purpose of the research and were given sufficient time to recall } \\
\text { and reflect on their cross-cultural service interactions. } \\
\text { Consistencies in themes were evident across the participants' } \\
\text { narratives and emergent themes were consistent from most of } \\
\text { the service providers and some guests. }\end{array}$ \\
\hline Conformability & \\
\hline $\begin{array}{l}\text { Extent to which interpretations are the result of the } \\
\text { participants and the phenomenon as opposed to the } \\
\text { researcher biases. }\end{array}$ & $\begin{array}{l}\text { Findings on the research were presented and discussed with } \\
\text { colleagues and peers for feedback. Authors also consulted back } \\
\text { on extant literature on themes and emergent themes from the } \\
\text { findings and independently went back into the data and further } \\
\text { explore the findings. }\end{array}$ \\
\hline Integrity & \\
\hline $\begin{array}{l}\text { Extent to which interpretations are influenced by } \\
\text { misinformation or evasions by participants. }\end{array}$ & $\begin{array}{l}\text { All research participants remain anonymous and they gave } \\
\text { consent to participate. Interviews were tape reordered, } \\
\text { transcribed and returned to participants who request to review } \\
\text { and make clarification. }\end{array}$ \\
\hline Fit & \\
\hline $\begin{array}{l}\text { Extent to which findings fit with the substantive area } \\
\text { under investigation. }\end{array}$ & $\begin{array}{l}\text { The findings from the study were checked against the research } \\
\text { questions and aims to see if they provide satisfactory answers. }\end{array}$ \\
\hline Undc & \\
\hline $\begin{array}{l}\text { Extent to which participants buy into results as } \\
\text { possible representations of their worlds. } \\
\text { Generality }\end{array}$ & $\begin{array}{l}\text { As it was not possible to provide the preliminary report to all } \\
\text { participants, the report was reported to three participants to seek } \\
\text { their understanding of the phenomenon under study. }\end{array}$ \\
\hline $\begin{array}{l}\text { Extent to which findings discover multiple aspects of } \\
\text { the phenomenon. }\end{array}$ & $\begin{array}{l}\text { The research design provided opportunities to gather holistic } \\
\text { perspectives to the phenomenon under study. The recruitment } \\
\text { criteria taking into considerations of } 3 \text { years luxury hotel } \\
\text { working experiences for service providers and } 3 \text { trips per years } \\
\text { for guests provided many critical incidents on cross-cultural } \\
\text { service interactions. }\end{array}$ \\
\hline & \\
\hline $\begin{array}{l}\text { Extent to which organizations can influence aspects of } \\
\text { the theory. }\end{array}$ & $\begin{array}{l}\text { As some of the research participants are from a luxury hotel, } \\
\text { theory is informed by that organization. }\end{array}$ \\
\hline
\end{tabular}




\section{Table 2: Participant profiles}

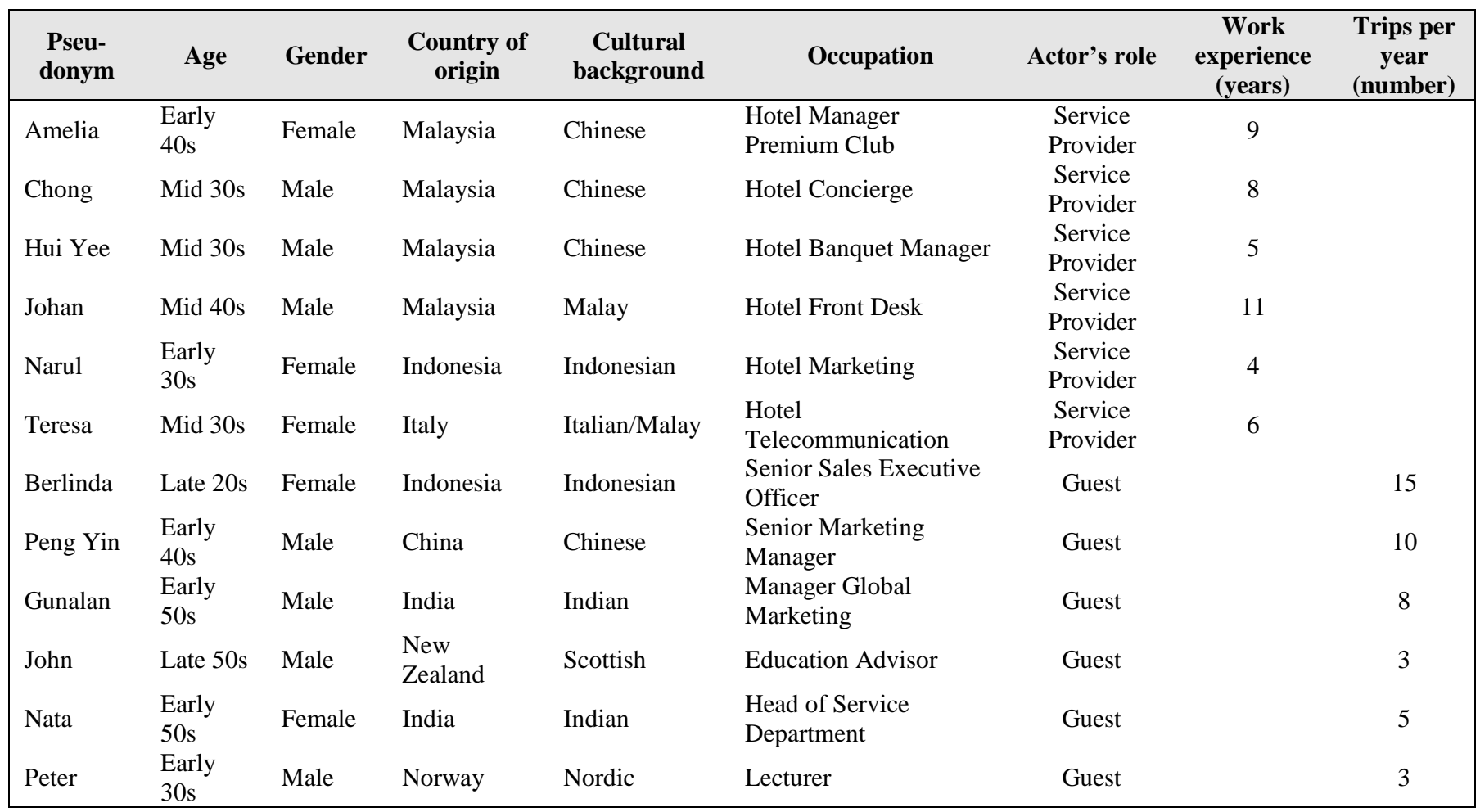




\section{Table 3: Narratives summary table}

\begin{tabular}{|c|c|c|c|}
\hline $\begin{array}{l}\text { Themes: } \\
\text { (first-order } \\
\text { narratives) }\end{array}$ & Name & Role & Comments \\
\hline \multirow[t]{5}{*}{ Actors' goals } & Chong & $\begin{array}{l}\text { Service } \\
\text { provider }\end{array}$ & $\begin{array}{l}\text {...cross-cultural service interaction is not a choice as it is part of my job. It is important to do my job } \\
\text { well. }\end{array}$ \\
\hline & Berlinda & $\begin{array}{l}\text { Guest on } \\
\text { business travel }\end{array}$ & $\begin{array}{l}\text {...when I travel on a long trip into a foreign country, I just want to settle into my room as quickly as } \\
\text { possible and get my things done... I don't really like to interact... }\end{array}$ \\
\hline & Peter & $\begin{array}{l}\text { Guest on } \\
\text { business travel }\end{array}$ & $\begin{array}{l}\text {... as long as the staff are able to check me into my room and that the room meets the amenities' } \\
\text { requirement, I will be happy... they don't need to entertain me... }\end{array}$ \\
\hline & Nata & $\begin{array}{l}\text { Guest on } \\
\text { leisure travel }\end{array}$ & $\begin{array}{l}\text {...When I travel, having fun and enjoyment is important. I like to explore the country, culture and } \\
\text { interact with the people... including people in the hotels... }\end{array}$ \\
\hline & Gunalan & $\begin{array}{l}\text { Guest on } \\
\text { leisure travel }\end{array}$ & $\begin{array}{l}\text {... for us, shopping and food are always the highlights. We always try to taste different types of } \\
\text { food and explore as many shopping centres as possible... }\end{array}$ \\
\hline \multirow[t]{4}{*}{ Control } & Johan & $\begin{array}{l}\text { Service } \\
\text { provider }\end{array}$ & $\begin{array}{l}\text {...some Singaporeans hoping to get things their way by showing they are in control start with "I } \\
\text { demand to speak to your manager" before they tell you the problem. }\end{array}$ \\
\hline & Amelia & $\begin{array}{l}\text { Service } \\
\text { provider }\end{array}$ & ...they insist on not being served by fellow South Asians if possible...to avoid social class issue... \\
\hline & Berlinda & $\begin{array}{l}\text { Guest on } \\
\text { business travel }\end{array}$ & $\begin{array}{l}\text {...You can get things done quicker...I always learn a few simple words like "good morning" and } \\
\text { "thank you" in the local language that always impresses them and gets them to be more helpful. }\end{array}$ \\
\hline & John & $\begin{array}{l}\text { Guest on } \\
\text { business travel }\end{array}$ & $\begin{array}{l}\text {...nothing works more magical than a smile ... a friendly smile can helps you deal with any situation with } \\
\text { a stranger better. }\end{array}$ \\
\hline \multirow[t]{4}{*}{ Power } & Narul & $\begin{array}{l}\text { Service } \\
\text { provider }\end{array}$ & $\begin{array}{l}\text {...some of them will raise their voice... to grab attention from the surrounding guests, creating a } \\
\text { scene in the hope of receiving a quicker check-in... }\end{array}$ \\
\hline & Hui-Yee & $\begin{array}{l}\text { Service } \\
\text { provider }\end{array}$ & $\begin{array}{l}\text {... some of the young and rich PRC Chinese...we call them the new rich-if they find a hair in their food, } \\
\text { they will shout, so that the other people can hear. While they don't want any compensation, they } \\
\text { certainly want to attract attention. }\end{array}$ \\
\hline & Gunalan & $\begin{array}{l}\text { Guest on } \\
\text { leisure travel }\end{array}$ & $\begin{array}{l}\text {...it's not common to dress in T-shirt and jeans [for professionals] in our culture, it is seen as less } \\
\text { formal.... if you want to get better attention in service, you need to dress formally...such as with suit and } \\
\text { ties, you get better treatment... }\end{array}$ \\
\hline & Pen Yin & $\begin{array}{l}\text { Guest on } \\
\text { leisure travel }\end{array}$ & $\begin{array}{l}\text {...if you speak English in China, they know you are from overseas... however, sometimes, in China if you } \\
\text { are a Malaysian Chinese speaking English, they think you are a show-off. }\end{array}$ \\
\hline $\begin{array}{l}\text { Emergent } \\
\text { Themes: } \\
\text { (second-order } \\
\text { narratives) }\end{array}$ & & & \\
\hline
\end{tabular}




\begin{tabular}{|c|c|c|c|}
\hline $\begin{array}{l}\text { Controlling } \\
\text { techniques: } \\
\text { Subjective } \\
\text { essentialism }\end{array}$ & John & $\begin{array}{l}\text { Guest on } \\
\text { business travel }\end{array}$ & $\begin{array}{l}\text {...Who knows what to expect... I was prepared to use sign language if necessary...I didn't expect them to } \\
\text { be able to understand and speak English. They spoke good English. I am impressed. }\end{array}$ \\
\hline & Pen Yin & $\begin{array}{l}\text { Guest on } \\
\text { leisure travel }\end{array}$ & $\begin{array}{l}\text {...just because I am a Malaysian Chinese, the hotel employees in China expect me to speak Mandarin } \\
\text { and know everything about the Chinese custom. I am sorry. Not all Chinese in Malaysia speak } \\
\text { Mandarin. }\end{array}$ \\
\hline & Chong & $\begin{array}{l}\text { Service } \\
\text { provider }\end{array}$ & $\begin{array}{l}\text {...I have not been to Australia... but I heard is very different from Malaysia... we don't expect them to } \\
\text { know about our Malaysian's customs and culture. }\end{array}$ \\
\hline \multirow[t]{3}{*}{ Stereotyping } & Johan & $\begin{array}{l}\text { Service } \\
\text { provider }\end{array}$ & $\begin{array}{l}\text {...just because it's a group travel... they always demand to have the same as their fellow group members. } \\
\text { They insist on having the same type of room as the others. }\end{array}$ \\
\hline & Teresa & $\begin{array}{l}\text { Service } \\
\text { provider }\end{array}$ & $\begin{array}{l}\text {...we learn from others [colleagues] that have faced the same situation in dealing with visitors from } \\
\text { Middle East. Usually they had misplaced the items in their room or their family have them but they } \\
\text { thought was stolen. }\end{array}$ \\
\hline & Narul & $\begin{array}{l}\text { Service } \\
\text { provider }\end{array}$ & $\begin{array}{l}\text {...my colleagues told me that guests from South Asian usually travel in large numbers and they love to } \\
\text { shop ending up having excess baggage...they also have poor time management that often results in late } \\
\text { check-ins and check-out. }\end{array}$ \\
\hline
\end{tabular}


